\title{
Enhancing Continuing Professional Teachers' Development in High Schools through Support and Monitoring Offered to Communities of Practice by Stakeholders
}

\author{
Adeola Folasade Akinyemi \\ Vuyisile Nkonki \\ Teaching and Learning Centre, \\ University of Fort Hare, \\ Alice, South Africa
}

DOI: https://doi.org/10.36941/jesr-2020-0124

\begin{abstract}
This study is located in pragmatic research paradigm and adopted mixed methods research approach to get in-depth information from participants on enhancing continuing professional teachers' development in high schools through support and monitoring offered to communities of practice by stakeholders. Semi-structured questionnaires and semi-structured interview were used as the research instruments to solicit information from seventy-nine participants selected as samples. The participants were purposely selected because of their involvement in communities of practice activities in their schools. The data were analysed descriptively using simple percentage tables for quantitative data while qualitative data were analysed thematically based on the themes that emerged. The findings of the study show that teachers received lot of support from education district officials and facilitators of communities of practice. The type of support received include organising content gap workshop for teachers, encouraging team work, helping teachers in difficult areas of their subjects and assist in difficult areas of facilitation. The findings of the study also indicate that support and monitoring measures in communities of practice helped teachers get feedback that assist them to know areas of their subject matter they need to address and improve on. Recommendations were made that district officials should go on regular class visits to monitor teachers to check if they are implementing what they have learnt in the communities of practice and regular on-site support should be provided for teachers by subject advisors.
\end{abstract}

Keywords: communities of practice, learning activities, support, monitoring, assisting, stakeholders

\section{Introduction}

Support and monitoring offered to communities of practice by stakeholders are very imperative and will go a long way to enhance continuing professional teachers' development (CPTD) in high schools. The various stakeholders that provide support and monitoring mechanisms to teachers include school principals, education officials (at local and district levels), Non-Governmental Organisations (NGOs) and international agencies (Mokhele, 2013). The amount of support given to teachers by these stakeholders will go a long way to help them towards their professional development (Chappius, 2007). Communities of practice is a school-based type of continuing teachers' professional development which give teachers the opportunities to interact, learn and collaborate as groups by assisting each other in areas concerning their professional development (Rodman, 2019). This implies that teachers 
engage in collaborative learning activities by assisting each other in their various schools. Chappius (2007) notes that teachers' professional development is more effective and practical when it is schoolbased which is mainly focused on active collaborative learning activities. Thus, in collaborative learning activities, there is need for support and monitoring to be given to teachers by various stakeholders. The stakeholders could be the education officials, school principals, facilitators of communities of practice, NGOs as well as international agencies. The support given to teachers by these stakeholders should be towards helping them to develop professionally.

Moreover, it is expected of the school leaders to identify suitable facilitators who will facilitate learning activities in professional learning communities, and adequate support must be given to them (Chappuis et al., 2009; Steyn, 2013). Experts and well experienced and skilled facilitators who will be able to give the best to teachers in terms of professional development must be made available by school leaders. Facilitators of communities of practice are expected to preserve their level of understanding, amount of attention and assistance so as to enable them to be dynamic in their given roles. Thus, principals must make available some provisions which will give opportunities for networking for facilitators like sequence of consistent consultations which will enable the facilitators to act as part of the group and interact also as a member of the group. They also plan for the group works and schedules. Principals must be occasionally informed on whatever programme(s) the facilitators are expected to do and the current stage of the programme, this will assist all the principals to have full information and status of the progress made by the teachers and to give adequate support accordingly (Chappuis et al., 2009). Fullan cited in Sparks (2003) state that as a way of supporting teachers in professional learning communities to enhance their development, some schools have to changed their timetables and weekly agendas to afford teachers to have fixed time to for mutual learning activities. Without this support from leaders, teachers will not have time to collaborate and learn with their colleagues. This support provides a basis for effective adult learning which helps to eliminate the hurdle of isolation among teachers which is the dearth effective teachers' professional development.

As part of the support to communities of practice, there is also a need to make resources available for teachers. These resources include teaching materials (textbooks, visual aids and writing materials) that will facilitate effective learning. Thus it is expected of the Department of Education (DoE) to finance each school to get the materials needed. This is a means of support rendered to communities of practice by the DoE. This financial support can be done through the local district education department, for instance, schools in Fort Beaufort Education District Eastern Cape Province of South Africa should get support from Eastern Cape Department of Education (ECDoE) in terms of the material resources they need in communities of practice. According to Anderson (2003), in professional development community, external provision and funding are more likely to be from assistance received locally from the region or neighbourhood. The importance of local school regions in intervening between departments and the management is indisputable (Spillane, 2002). Massell (2000) argues that school districts are key elements and authorized agents that oversee and guide schools and act as a mediator between the national level and district level.

In addition, in professional learning communities, support can also be provided to teachers to enhance professional development through funding from international bodies and NGOs. School leaders and the DoE alone cannot support professional learning communities. There is the need for other stakeholders to support the learning activities in the communities. This can be done by funding received from the stakeholders as the government alone cannot fund education. Bolam et al. (2005) state that many schools have built productive relationships with a variety of partners in terms of support they get from them. Engels (2001) revealed that the USAID, an international agency, supports teacher clusters through funding, which in turn improves teacher practices.

Besides, the kind of monitoring measures offered to teachers by their school leaders, education officials, facilitators and other stakeholders will go a long way to assist them in their professional development. Chappius et al (2009) note that it is imperative for school heads to offer individualised support to teachers through motivation and monitoring their work related activities. This invariably means instructional leadership school heads can give to their teachers through support and monitoring 
measures given to them to assist them in various areas like subject matter or classroom management. It is the expectation of the school heads to ascertain essential things needed by teachers in communities of practice to assist them in relation to their professional development. Subsequently, those needs must be provided through supportive measures through motivation and monitoring to see if those needs are adequately met. As stipulated in national policy framework (DoE, 2008), monitoring of teaching and learning activities in communities of practice is expected to be done by education district officials. The main idea of the policy is to serve as support mechanism and to aid the procedure of professional development towards refurbishing teaching career through classroom management and acquiring new skills.

In addition, it is expected that's school heads provide monitoring measures to teachers in communities of practice towards the end of teaching and learning period which may be monthly or termly. This monitoring measure is like a follow-up to see how teachers are coping with teaching and learning activities, what they have achieved in terms of their work load and to see ways or areas they need assistance. Steyn (2011) points that it is very vital for school principals to monitor and give feedback to teachers at the end of professional development programmes in their schools. This is to know how teachers have put into practice various skills they have learnt. The feedback they get will assist them to adjust in areas where expected and this will also give them confidence to seek for further assistance if required. Support and monitoring offered to communities of practice by stakeholders is indispensable in enhancing continuing professional teachers' development in high schools. Thus, this study seeks to investigate enhancing continuing professional teachers' development in high schools through support and monitoring offered to communities of practice by stakeholders in Fort Beaufort Education District, Eastern Cape Province, South Africa.

\section{$1.1 \quad$ Objectives}

In order to examine the support and monitoring offered to teachers' professional development by various stakeholders, this study was guided by some objectives. The main objective of this study was to examine how continuing professional teachers' development are enhanced in high schools through support and monitoring offered to communities of practice by stakeholders. The specific objectives are:

- to state support provided by education district officials to communities of practice,

- to mention type of support received from education district officials to communities of practice,

- to explain support received from facilitators of communities of practice,

- to state type of support received from facilitators of communities of practice and

- to explain the benefits of support and monitoring in communities of practice.

\section{Research Methodology}

This study adopted mixed methods research approach and concurrent triangulation research design. The use of mixed methods assist the researchers to use different data instruments to get adequate views from participants (Frels, \& Onwuegbuzie, 2013). Mixed methods entail collecting data using both qualitative and quantitative methods, thus, sufficient information were gotten from the respondents on enhancing continuing professional teachers' development in high schools through support and monitoring offered to communities of practice by stakeholders. The data collection instruments used were questionnaires, interview guides for face to face interview conducted and document reviews were done looking at the meetings of communities of practice activities, materials used by facilitators and record books of facilities used in selected schools.

Ten schools were purposely selected out of total number of forty schools in Fort Beaufort Education District. The schools were selected because of their engagement in communities of practice 
activities. Seventy-nine participants including teachers, heads of departments, principals, cluster leaders, subject advisers and education district official were randomly selected for both qualitative and quantitative data because of their involvement in communities of practice activities in their schools. Sixty- four participants selected to get quantitative data, questionnaires were given to them to complete to give information on support and type of support received from education district officials, support and type of support received from facilitators of communities of practice and benefits of support and monitoring. Also, a total number of fifteen participants were interviewed to get expedient information from them for qualitative data on their views on support and monitoring offered to communities of practice.

Ethical considerations were observed when collecting data, thus all the respondents remained anonymous, hence their real names or identities were not revealed in this study, rather acronyms were used for all the participants (Creswell 2014). Likewise, consent forms were given to all the respondents to give their consent for participating in this study, confidentiality was also observed and the respondents were given permission to withdraw from participating in the study when they felt they are not comfortable. The data were analysed descriptively using simple percentage tables for quantitative data while qualitative data were analysed thematically based on the themes that emerged (Harrison et al., 2018)

\section{Results}

This study endeavored to answer the main objective which sought to examine how continuing professional teachers' development are enhanced in high schools through support and monitoring offered to communities of practice by stakeholders in high schools in the Fort Beaufort Education District. Nonetheless, this study gives information of the specific objectives which were; to state support provided by education district officials to communities of practice, to mention type of support received from education district officials to communities of practice, to explain support received from facilitators of communities of practice, to state type of support received from facilitators of communities of practice and to explain the benefits of support and monitoring in communities of practice. The respondents were abbreviated in this paper as Tr-Tr3, Pr-Pr3, CL1-3, HOD1-3, SA1-2 and EDO for teacher, principal, cluster leader, head of department, subject advisor and education district official respectively. The findings are presented below.

\subsection{Support Provided by the Education District Officials to Communities of Practice}

The study sought further to investigate support provided by education district officials to the communities of practice in various schools. The respondents (teachers, heads of departments, cluster leaders and principals) were asked if their schools have received any support from education district officials. The results are presented in Table 1 below.

Table 1: Support received from education district officials in communities of practice

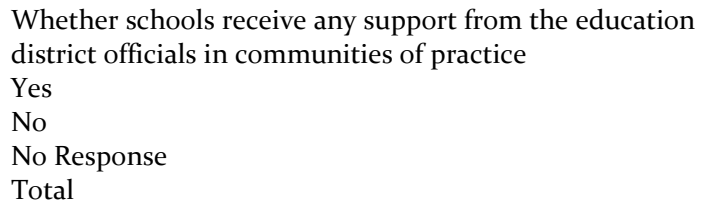

$\begin{array}{cc}\text { Frequency } & \text { Percentage } \\ 61 & 95.31 \\ \text { o } & 0.00 \\ 3 & 4.69 \\ 64 & 100.00\end{array}$

Table 1 reveals that majority of the respondents, 61 (95.31\%) responded that their schools have received support from education district officials while the remaining three respondents $(4.69 \%)$ did not respond to the question. 
All the participants interviewed also said they have received support from education district officials in their communities of practice in their schools and with other schools. Their comments are in agreement with the responses from quantitative data. Some of their comments are as follows.

Tri commented:

We have received support from them so many times both in the school and even at the district level.

Tr2 said:

Yes, they give us support whenever we need call for it. Teachers in school cannot do everything alone as a group, we still need their support for guidance in our work.

HOD 1 remarked:

Support come from them often to make sure things are in order within the school and that teachers are doing well and there is improvement in their teaching activities.

CL2 said:

Yes, we get support from them constantly and this help to get good result from the teacher meetings in schools and cluster meetings at the district.

Most of the participants indicated that they received support from the education district officials. The good thing from their responses is that the support they got were not only limited to communities of practice in schools alone but across the clusters and up to the district.

\subsection{Type of Support Received from Education District Officials in Communities of Practice}

The study sought to further establish the types of support received from education district officials in communities of practice. The data are presented in Table 2 below.

Table 2: Type of support received from education district officials' in communities of practice

Type of support received from district officials in communities of practice

They arrange for special meetings once in a while to meet and discuss with teachers

Subject advisors often visit the schools and sometimes teach subjects with no or few staffs

They organize content gap workshops

They offer assistance in terms of materials and funds

Total

$\begin{array}{cc}\text { Frequency } & \text { Percentage } \\ 24 & 37.50 \\ 10 & 15.63 \\ 12 & 18.75 \\ 18 & 28.12 \\ 64 & 100\end{array}$

The data from Table 2 above indicate that $24(37.50 \%)$ respondents said they received support from education district officials in form of special meeting arranged for teachers once in a while in their schools' communities of practice, while $10(15.63 \%)$ respondents said the subject advisors sometimes teach subject with no or few teachers in their schools, $12(18.75 \%)$ participants said the district officials organized content gap workshops while $18(28.12 \%)$ indicated that they get assistance from education district officials in terms of materials and funds.

The responses from the respondents showed individual support given to teachers by the education district officials which is really what they are supposed to do. It was evident from the data above that the type of support teachers mentioned here are the ones they received from the education district officials in the formal cluster communities of practice which was specifically organized by the department of education to enhance CPTD. The support includes special meetings with teachers to discuss their work, teaching of subjects with few or no teachers by subject advisors, organizing content workshops and support in form of educational materials and funds. Such support is expected to be 
extended to teachers in their various schools as a way of giving on-site support to teachers in their schools.

\subsection{Support Received from Facilitators of Communities of Practice}

The study further sought information from teachers, heads of departments, cluster leaders and principals to indicate the support received by communities of practice (formal and informal) from facilitators. Table 3 below shows the result.

Table 3: Support received from facilitators of communities of practice

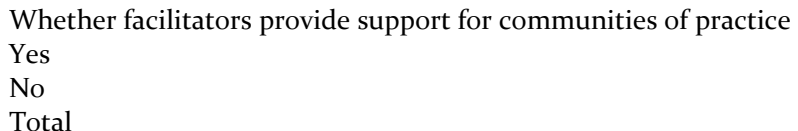

$\begin{array}{cc}\text { Frequency } & \text { Percentage } \\ 62 & 96.88 \\ 2 & 3.22 \\ 64 & 100.00\end{array}$

The results from Table 3 above reveals that majority of the respondents, 62 (96.88\%) responded positively to the question while only two respondents $(3.12 \%)$ said they do not get support from facilitators of communities of practice.

Support received from facilitators of communities of practice was confirmed in the interviews with the participant teachers, HODs principals, cluster leaders and district officials. They also said they received support from the facilitators in communities of practice in their various schools, clusters and district. Their comments are given below.

Tr3 said:

Support of diverse forms come from the facilitators, they are willing to assist teachers to be develop in their subjects.

HOD 2 replied:

Yes, we get support from them often and they are easily accessible if you need their help too.

Pr2 commented:

The facilitators have helped us a lot, despite the fact that our teachers are the facilitators, they still have the experience to assist other teachers within the school and some within the cluster and even up to the district level. They facilitate both formal and informal meetings in schools and other schools. Teachers have improved in their work, content knowledge and methodologies through their support.

CL1 remarked:

Most of the support we get in schools come from them, so I will say yes, they support very well.

SA2 said:

Of course so many high schools have received support from the facilitators of this programme and they are still getting support from them and we are seeing the result in teacher performances.

EDO indicated that:

Yes, high schools in this district have received a lot of support from the facilitators both within their schools and outside the schools. It is actually a good initiative most especially schools that meet as a group on their own to advance and develop themselves. You will not be surprised that sometimes, they choose someone among the teachers to facilitate the programme and they do it well. They get us involved 
as the district officials for more support and when materials are needed.

It was established that communities of practice within the school and between schools either formal or informal ones get help from the facilitators. The good thing that emerged is that sometimes in some of the schools, experienced teachers were chosen to facilitate the programme, and they do so effectively, according to the participants.

\subsection{Type of Support Received from Facilitators of Communities of Practice}

The participants were further asked to describe the support they have received from the facilitators of communities of practice. Their responses are shown in Table 4 below.

Table 4: Type of support received from facilitators of communities of practice

Form of support received from facilitators of communities of practice

Assisting in the facilitation of the learning activities

Helping teachers in difficult areas of their subjects and guidance services for teachers

Monitoring the activities engaged in during the programme

Encouraging team work, identifying areas of weakness and organizing practical sessions for such areas

Total

$\begin{array}{cc}\text { Frequency } & \text { Percentage } \\ 30 & 46.88 \\ 21 & 32.81 \\ 5 & 7.81 \\ 8 & 12.50 \\ & \\ 64 & 100.00\end{array}$

The responses in Table 4 above show that 30 (46.88\%) respondents received support in form of facilitation of learning activities, $21(32.81 \%)$ respondents indicated the facilitators helped teachers in difficult areas of their subjects and provide guidance service for teachers, $5(7.81 \%)$ participants received support in form of monitoring of activities they engaged in during the programme by facilitators of communities of practice and $8(12.50 \%)$ respondents said the facilitators encourage team work identified areas of weakness and organized practical sessions for such areas.

The in-depth interviews with the participants also revealed different types of support they have received in communities of practice.

Tr1 said:

The facilitators coordinate the group activities and encourage us to work as a team by grouping us in a group and we work and discuss as a group.

HOD3 commented:

They monitor all the learning activities we engage in and at the same time they attend to teachers' comments and questions on areas that are not clear to them. They sometime give one on one support to teachers.

CL3 said:

The group activities are coordinated by them and other teachers to make sure things go well the way it should. In some cases, they assist teachers on how to plan their lessons and manage their classes

SAl commented:

They support teachers in high schools by facilitating the programme, organize for special sessions in form of training or workshop. The facilitators also support the teachers by advising and encouraging them the need to be a part of the programme with other teachers so as to increase their knowledge in their various subjects.

EDO stated: 
Facilitators of the programme motivate, encourage, guide and assist teacher in their subjects, how to learn and work as a group and at the same time how to be a professional in their teaching career.

The findings revealed that most of the teachers get various support from the facilitators of formal and informal communities of practice in form of content gap workshops, advising and encouraging teachers to work as teams and to be part of both formal and informal communities of practice which helped them in their professional development. It was also indicated that the facilitators of the formal and informal communities of practice facilitate the learning activities along with some teachers where they guide and assist teachers in their various subjects.

\subsection{Benefits of Support and Monitoring}

The study sought to find out information about the benefits of support and mechanisms in communities of practice. Table 5.34 below shows the responses of the respondents.

Table 5: Benefit of support and monitoring

\begin{tabular}{|c|c|c|}
\hline $\begin{array}{l}\text { Whether communities of practice benefit from support and monitoring from } \\
\text { principals and the department of education }\end{array}$ & Frequency & Percentage \\
\hline Yes & 59 & 92.19 \\
\hline No & 5 & 7.81 \\
\hline Total & 64 & 100.00 \\
\hline
\end{tabular}

Table 5 above reveals that $59(92.19 \%)$ respondents said the support and monitoring mechanisms are beneficial to the communities of practice in their schools, while $5(7.81 \%)$ respondents said the support and monitoring mechanisms are not beneficial.

The participants interviewed were asked how beneficial the support and monitoring mechanisms are. Their responses revealed that they are, in fact, very beneficial. The school teachers interviewed said the mechanisms are beneficial as they offer guidance and bring about improvements in their work. Their responses also complement the data from the quantitative data above in table 5.33.

Tri noted:

They are beneficial because this is what guides us to always keep in check and to do what is expected. The one on one support received has also helped personally, teachers are able to confide in school heads or district officials' different areas that need to be addressed.

Tr2 said:

This helped us a lot. We know how far we have helped ourselves, what we have achieved and areas that we need improvement. Thus, there is usually a time to evaluate the activities of the group members.

In their responses for their interviews HOD 1 and $\mathrm{HOD}_{3}$ spoke about benefits of the monitoring mechanism, according to them, it has helped them to learn new things and improve on their performances.

$\mathrm{HOD}_{3}$ remarked:

They are so beneficial. It is like an eye opener, we have learnt many new ways and have new ideas of doing things related to teaching and learning activities.

HOD2 was the only one that spoke about benefit of support and monitoring mechanism in communities of practice.

$\mathrm{HOD} 2$ said: 
I will say the support and monitoring mechanisms are good. We get materials we need and through monitoring we know our lapses and we sit up to address such lapses.

The cluster leaders also have the following to say about the benefit of support and monitoring mechanisms offered to teachers in communities of practice.

CLi commented:

Very effective, we get feedback which helps us to know which areas to address and improve on.

CL3 revealed:

It has helped us to make adjustment and improve on areas that we think we are not performing well or up to expectation or standard.

School principals interviewed also concurred with the responses of the teachers, heads of departments and cluster leaders. They also said the support and monitoring mechanisms have helped teachers to develop and have time to participate in communities of practice meetings.

Pr1 pointed out:

So far the monitoring and support mechanism have helped teachers to develop and have time to participate in learning activities in group meetings.

Pr2 affirmed:

Yes, we usually benefit. The tasks are usually moderated if it is up to standard and check the policy document and the task will fit in for each term.

The district officials were also interviewed to find out if the support and monitoring offered to teachers in communities of practice are beneficial. The responses they gave confirm what other participants have said. They said the mechanisms are beneficial, activities of teachers in communities of practice are monitored and the teachers are also given extra support for them to perform very well in their work, thus enhancing professionalism. It is also a way of correcting teachers in any aspect of their work which they are not getting right.

SAı disclosed:

I could say yes, they are beneficiary because what is happening, if we found that this very teacher after we have monitored him or her, he or she is still struggling to implement, then the subject advisor will set an appointment with the school in two or three days, the subject advisor will go there and help the individual teacher in school. They are beneficiary because we are giving extra support to teachers.

SA said:

They benefit a lot because it means we are not letting teachers do what they like and what they do not know. We as the subject advisors we are working by the policy, we ensuring the policy of the department of education are correctly implemented. You know, some teachers are not having directions at times, they just jump to a class only to find out that the specific roles of doing it and of implementing it are neglected. By monitoring and supporting that is how we want to correct them should there be a need to do so.

EDO remarked:

Support and monitoring mechanism are beneficiary to teachers and to our program. When we support teachers with materials, we need to visit and monitor how they are utilizing those materials. In fact, if we do not monitor the program, how do we know what they need to the extent of supporting them? We give moral support by doing regular visit to schools to know how teachers are faring in their school work. Materials are also given to equip them. These have helped to evaluate teacher performance and our 
programme. I tell you, we have improved and learnt a lot. The support and monitoring mechanism are so beneficial, you see where things are right and when things are wrong.

From the comments and discussion with the participant teachers, heads of departments, cluster leaders, principals and district officials, it has been established that the support and monitoring offered to both formal and informal communities of practice as one of the strategies used to enhance continuing professional teachers' development has really helped teachers who are group members. Formal communities of practice, that is, the cluster meetings have been supported with material and financial resources from the district of education which is actually what they are expected to do. However, some of the teachers and principals said they sometimes take money from their pocket for communities of practice activities, most especially when they want to go for informal communities of practice in some high schools. The same is applicable to formal communities of practice in form of subject association established by schools. The teachers sometimes finance the expenses of their transport and procurement of some educational materials to be used. Most of the support they get are mainly from teachers in the schools.

The researchers were able to analyze some documents at the district office which show the support the district office has offered to some schools in terms of educational materials given to them to empower teachers for professional development as part of what is expected by the department of education to develop teachers. The educational materials given to them are meant to aid their teaching and learning activities which will enhance CPTD in all the high schools in each cluster.

\section{Discussion}

Support and monitoring given to communities of practice will help to enhance teachers' professional development. The current study found that most of the sampled high schools received support in their communities of practice from education district officials. The study further found that the support they received from the education district officials include assisting teachers by supporting them in areas where they experiencing weakness; visiting schools and layout programmes; organizing content gap workshops; arranging for special meetings sometimes to meet and discuss with teachers; coming to schools to teach subjects that are short-staffed; providing educational materials and also assisting teachers that have problems with their subjects; and organizing workshops for teachers. The findings of the study are in support of literature reviewed as Anderson (2003) in his study on professional community literature notes that external support tends to come mainly in form of the district support as the district officials support the professional community in form of educational materials and moral support. This implies that support received from education district officials will go a long way to help communities of practice in enhancing CPTD.

The findings of the study further showed that at cluster level, teachers meet for FET moderation where teachers come with evidence of their work in terms of what they have been doing in a particular term. The subject advisors monitor and moderate the teachers work and from there they pick the challenges teachers are facing. Thus, through lapses observed in teachers work through monitoring mechanism, workshops are organized for teachers to address such challenges. It was also revealed that the workshops organized are anchored either by experienced teachers with the assistance of the district officials or the workshop are being facilitated by experts to assist teachers to improve on their weak areas. This is a good strategy put in place by the district officials to support formal communities of practice.

Chappuis et al. (2009) note that in communities of practice, appropriate facilitators must be made available and the facilitators must also give adequate support to teachers in order to enhance CPTD. The study found that majority of the participants received support from the facilitators of communities of practice which has enabled them to improve on their professional development. The support they received from the facilitators are helping teacher in difficult areas of their subjects, provision of guidance services for teachers, provide teachers with material resources, helped teachers to organize 
lessons, one on one support for teachers, support teachers with training sessions, organize content gap workshop, encouraging team work and identifying areas where there are gaps and organized practical session for such areas. The findings of the study align with literature reviewed as it is expected of an effective facilitator to have a clear understanding of their roles and responsibilities which includes monitoring how group members participate and also their abilities in aiming and assisting dynamic deliberations and investigation which would promote the group members in their collaborative learning activities (Kaner, \& Wright, 2009; McDonald, Mohr, Dichter, \& McDonald, 2007). Support received from facilitators of communities of practice, therefore, has a positive impact in enhancing CPTD in schools.

Nevertheless, the findings of this study indicate inadequate support from departmental officers as well as from facilitators are encountered in communities of practice. It is expected that the departmental officials should support teachers in cluster meeting as a way of assisting them to develop professionally. This support should be protracted to schools that subject advisors are likely to do field support and classroom visitation and see ways to support teachers with their content and approaches to teaching. The results of the study shown that subject advisors did not have chance to visit some schools. Some teachers had to sought for assistance from their colleagues when they had challenges. Also, it was discovered that some teachers did not get help from organisers of formal cluster consultation who are chiefly the subject advisors. These subject advisors see their duties to be more of monitoring rather than supportive, thus most times, they allotted the duties of facilitating to skilled teachers from different schools. This means teachers have to rely on their colleagues for assistance on learning activities in their communities of practice.

Chappuis et al. (2009) note that support and monitoring are essential in communities of practice as a strategy to enhance CPTD. The support and monitoring mechanisms from the school leaders, facilitators, district officials and other stakeholders are very important as they will be beneficial to the communities of practice members to improve on their professional development. The study found that the support and monitoring offered to communities by schools and other stakeholders are beneficial to group members because it helps to guides them to always keep in check and to do what is expected. It was also revealed that one on one support they receive also helps them personally in terms of professional development. It emerged that teachers are able to confide in their school heads and district officials about the different areas of their work or subjects they were having challenges in which need to be addressed.

The information gathered also revealed that in the sampled high schools, support and monitoring helps teachers and enables them to measure their professional development in terms of assistance they have rendered to group members and the assistance they have received from other group members in informal communities of practice. The mechanisms also helped them to know what they have achieved as a group through evaluation of their progress and areas where there are lapses that need improvement. This is usually the time to evaluate the activities of the group members and see what to do to enhance teachers' professional development in areas that need improvement.

It was also established that support and monitoring have brought about development in communities of practice in some of the sampled high schools. The data gathered revealed that learning activities are monitored by school heads and district officials in communities of practice, and the educational materials needed are provided. Trainings are also organized to help teachers in areas where they need help especially in terms of content knowledge. This helps the group members as they get good results and the mechanism helps to bring about an avenue for identifying and addressing various problems which the teachers face, and provide necessary solutions.

The findings of current study further show that the support and monitoring have helped teachers to develop and have time to participate in learning activities for the group meetings. Teachers were given time to attend and participate in learning activities in communities of practice by school heads as a way to support them to enhance CPTD. The findings of the study are in line with literature reviewed as Fullan cited in Sparks (2003) notes that in order to enhance CPTD, some school districts have altered the school calendars as a way of supporting teachers to attend professional development 
meetings by giving them time to attend without clashing with school time tables. The group members also benefit from the support and monitoring mechanisms as the tasks assigned to group members are also moderated if it is up to standard and if it is in line with the policy document as recommended by the department of education. This indicates that support and monitoring are essential in communities of practice and must be offered to teachers in high schools so as to enhance CPTD. It was established from the findings of the study that support and monitoring strategy offered to communities of practice by school heads and other stakeholders helped to enhance CPTD in schools.

\section{Conclusion}

Based on the results of the study conducted, the researchers found that most of the sampled high schools received support from district officials. The support they received included visitation to school and layout of programs, organizing content gap workshops, provision of educational materials, arranging for special meetings for teachers once in a while to meet and discuss on their school work and onsite support for teachers by subject advisors. Though, the findings of the study revealed that adequate support from some officials from the department as well as facilitators was lacking in communities of practice. Most schools do not get support from the support advisors as expected. It was found that some schools were never visited by the subject advisors for classroom visit and on-site. Also, it was discovered that some teachers did not get adequate support from facilitators of cluster meeting who were mainly the subject advisors. Rather, teachers depended on their colleagues for support on learning activities in communities of practice. The findings also revealed that teachers get support from experienced teachers in their schools and other schools who have the skills and the expertise to facilitate communities of practice. The study found that the support and monitoring mechanisms offered to communities by schools and other stakeholders were beneficial to group members. The mechanisms guide them and keep them in check on what was expected of them in terms of activities they engaged in communities of practice to enhance CPTD.

\section{Recommendations}

Collaborative learning activities are being encouraged in communities of practice, hence such activities must be sustained with sufficient funding and provision of infrastructural facilities by the department of education. Also, the facilitators should conduct one on one support for teachers who really need help with their teaching methodologies and classroom management. Frequent on-site supervision should be conducted by supervisors to monitor and support teaching and learning activities in schools' communities of practice. Principals and education district officials must ensure thorough supervisory and monitoring measures in schools to check if teachers are implementing what they have learnt in the communities of practice.

\section{References}

Anderson, S. E. (2003). The school district role in educational change: A review of the literature. Toronto: International Centre for Educational Change, Ontario Institute for Studies in Education.

Bolam, R., McMahon, A., Stoll, L., Thomas, S., Wallace, M., Greenwood, A., \& Smith, M. (2005). Creating and sustaining effective professional learning communities. London: Department for Education and Skills.

Chappuis, S., Chappius, J., \& Stiggins, R. (2009). Supporting teacher learning teams. Association for supervision and Curriculum Development, 66(5), 56-6o.

Chappuis, J. (2007). Learning team facilitator handbook. Portland, OR: Educational Testing Service.

Creswell, J. W. (2014). Research Design. Qualitative and Quantitative and Mixed Approaches (4 ${ }^{\text {th }}$ ed.). Thousand Oaks, CA: Sage.

Department of Education. (2008). Foundations for Learning Campaign. Pretoria: Government Printer.

Engels, J. (2001). Making classrooms talk: Uganda sustains its teacher improvement and support system. Washington, DC: Academy for Educational Development. 
Frels, R. K., \& Onwuegbuzie, A. J. (2013). Administering quantitative instruments with qualitative interviews: A mixed research approach. Journal of Counseling \& Development, 91(2), 184-194.

Harrison, A. L., Taylor, N. F., Shields, N., \& Frawley, H. C. (2018). Attitudes, barriers and enablers to physical activity in pregnant women: a systematic review. Journal of physiotherapy, 64(1), 24-32.

Kaner, S., \& Wright, D. (2009). Working effectively in groups: Developing your collaborative mindset. In J. Bandrowski, Discover your inner strength. Seveierville,TE: Insight Publishing.

Massell, D. (200o). The district role in building capacity: Four strategies. Philadelphia: Consortium for Policy research in Education, Graduate School of Education, University of Pennsylvania.

McDonald, J. P., Mohr, N., Dichter, A., \& McDonald, E. C. (2007). The power of protocols: An educator's guide to better practice. New York: Teachers College Press.

Mokhele, M. L. (2013). Empowering Teachers: An Alternative Model for Professional Development in South Africa. Journal of Social Science, 34(1), 73-81.

Rodman, A. (2019). Personalized Professional Learning: A Job-Embedded Pathway for Elevating Teacher Voice. ASCD.

Sparks, D. (2003). Change agent: An interview with Michael Fullan. Journal of Staff Development, 24(1), 55-58.

Spillane, J. P. (2002). Local theories of teacher change: The pedagogy of district policies and programs. Teacher College Record, 104, 377-420.

Steyn, G. M. (2011). Continuing Professional Development in South African Schools: Staff Perceptions and the Role of Principals. Journal of Social Science, 28(1), 43-53.

Steyn, G. M. (2013). Building Professional Learning Communities to Enahnce Continuing Professional Development in South Africa Schools. Anthropologist, 15(3), 277-289. 